\title{
Relación entre prácticas pedagógicas de educación inicial con De Cero a Siempre
}

Relationship between Early Education Pedagogical Practices and "De Cero a Siempre"

Artículo de investigación | Research article

Fecha de recepción: 22 de abril de 2020

Fecha de aceptación: 13 de julio de 2021

Fecha de disponibilidad en línea: noviembre de 2021

doi: 10.11144/Javeriana.m14.rppe

Ángela Patricia Vargas-González ap.vargas@uniandes.edu.co

Universidad de los Andes, Colombia D ORCID: https://orcid.org/0000-0001-9116-3136

Para citar este artículo | To cite this article Vargas-González, A. P. (2021). Relación entre prácticas pedagógicas de educación inicial con De Cero a Siempre. magis, Revista Internacional de Investigación en Educación, 14, 1-30. doi: 10.11144/Javeriana.m14.rppe 


\title{
Resumen
}

En este artículo de investigación se analiza la relación entre prácticas pedagógicas de la modalidad institucional de la educación inicial colombiana con los lineamientos educativos del programa De Cero a Siempre. Metodológicamente se realizó un estudio de caso comparativo (ECC), en el que se analizaron 36 prácticas pedagógicas con el método de comparación constante de la teoría fundamentada constructivista. Los principales resultados muestran que, aunque en las prácticas pedagógicas se mantiene una tradición mimética, que se contradice con los postulados de la política educativa, se atisban modos de relacionamiento basados en el respeto y reconocimiento del otro.

\section{Palabras clave}

Educación de la primera infancia; práctica pedagógica; política educativa; Colombia.

\begin{abstract}
This article analyzes the relationship between pedagogical practices of the Colombian early childhood education system and the educational guidelines of "De Cero a Siempre" (From Zero to Always). A Comparative Case Study (CCT) was carried out, in which 36 pedagogical practices were analyzed with the Constant Comparison Method of Constructivist Grounded Theory. The main results showed that: although a mimetic tradition is maintained in pedagogical practices, which contradict the educational policy, some relations can be glimpsed based on respect and recognition of the other
\end{abstract}

\section{Keywords}

Early childhood education; teaching practice; educational policy; Colombia. 


\section{Descripción del artículo | Article description}

En este artículo de investigación se presentan los resultados de la investigación La política en las prácticas: análisis de las prácticas pedagógicas en la modalidad institucional de educación inicial en Colombia y su relación con la política pública De Cero a Siempre.

\section{Introducción}

Los principales hallazgos derivados de la revisión de los antecedentes sobre políticas educativas y prácticas pedagógicas muestran una distancia entre ambas, porque si bien las primeras tienen como objetivo orientar y ayudar a transformar, las segundas fijan expectativas a la labor de los docentes, que no responden a las necesidades de las prácticas pedagógicas ni a los contextos en los que estas se despliegan (Alaníz-Hernández, 2014; Garcés-Gómez \& Jaramillo-Jaramillo, 2008; Jaimes-Carvajal \& RodríguezLuna, 2015; Navas-Gómez \& Reynoso-Jaime, 2015; Subirats et al., 2008; Viscaíno, 2006). En otros casos, esta distancia se da porque la calidad de las prácticas pedagógicas se evalúa exclusivamente a partir de los parámetros oficiales sobre el deber ser de las mismas (Amaro, 2014; Martínez-Rizo, 2012; Vidiella \& Larraín, 2015). Algunas veces, esta distancia también se presenta porque no se reconoce a las prácticas pedagógicas como un componente fundamental en la realización de las políticas educativas, ni a los docentes como agentes de esta política (Asprella, 2016; Del Castillo-Alemán, 2012; Flores-Crespo, 2013; Heras, 2015; Pérez-Castro; 2009; ValenciaAguirre, 2009).

Esta realidad pone de manifiesto que en el centro de la discusión están los docentes, junto con los demás actores que forman parte de la práctica pedagógica, puesto que son ellos los encargados de interpretar y actualizar, en la vida cotidiana de las instituciones educativas y en las aulas de clase, lo que se propone en los documentos normativos y en los lineamientos de las políticas educativas. En este sentido, las políticas educativas no se restringen a prescripciones que se ejecutan tal y como fueron formuladas originalmente, así como tampoco las prácticas pedagógicas se limitan a ser el lugar de aplicación de las políticas educativas.

Lo anterior permite plantear que la relación entre políticas educativas y prácticas pedagógicas se da en el marco de la mutua determinación, dado que se trata de un proceso de construcción dinámico, que se hace tangible en función de las decisiones cotidianas que toman los diversos actores educativos y que se traduce en acciones pedagógicas (Heras, 2015). Comprender la política educativa desde la perspectiva expuesta implica 
reconocer el nivel de incertidumbre que se da cuando las acciones políticas se concretan en la vida cotidiana de las escuelas, en grupos específicos que actúan desde sus marcos de referencia, intereses, conocimientos, contradicciones y resistencias, entre otros (de Castro-Cerqueira, 2016; de Souza, 2016; Miranda-Camacho, 2006; Patel, 2016; Ponce-Grima, 2009; RobledoCastro, 2015).

Precisamente, en esa perspectiva de política educativa, denominada teóricamente como política educativa de lo cotidiano (Asprella, 2016; Heras, 2015; Menezes-Viana et al., 2015; Unamuno, 2015), se inscribe este proyecto de investigación "la política en las prácticas: análisis de las prácticas pedagógicas en la modalidad institucional de educación inicial en Colombia y su relación con la política pública 'De Cero a Siempre'", el cual tiene como objetivo central indagar la relación entre las prácticas pedagógicas de la modalidad institucional en Colombia y los lineamientos educativos de la política pública dirigida a la primera infancia colombiana.

De Cero a Siempre es la política de Estado para el desarrollo integral de la primera infancia colombiana que, desde una perspectiva de derechos y enfoque diferencial, propone un conjunto de acciones nacionales y territoriales para promover y garantizar el desarrollo infantil de los niños de acuerdo con sus contextos, condiciones y edades (Presidencia de la República, Colombia, 2012).

Comprender la relación expuesta permite visibilizar los conocimientos que se construyen desde las prácticas pedagógicas, para así tener una visión más amplia de la educación inicial en Colombia y de las acciones públicas que dan respuesta a las demandas sociales en este campo. Esto se constituye como una oportunidad para enriquecer el campo de la investigación sobre políticas educativas y prácticas pedagógicas para la primera infancia en Colombia, pues su desarrollo es incipiente, en relación con otros campos de la educación en el país, y por eso se requiere abrir caminos que permitan deconstruir las nociones de niño y de educación actualmente incorporadas en el sistema educativo.

Para lo anterior, es necesario generar espacios de diálogo entre múltiples perspectivas y aproximaciones metodológicas en el campo de la educación y de las prácticas pedagógicas en educación inicial, que conjuguen investigaciones enfocadas en diagnosticar y evaluar las políticas educativas y las prácticas pedagógicas con investigaciones que promuevan en los docentes una mirada crítica sobre su propia praxis, para así "abonar el terreno para la construcción de saber pedagógico propio del nivel, generando un cambio de paradigma [...] de una educadora técnica repetitiva, a una educadora profesional que reconstruye y mejora sus prácticas" (Vergara-Arboleda, 2014, p. 119). 
Sobre dichos conocimientos se centra este artículo, que está organizado de la siguiente manera: en el primer apartado, se desarrollan los dos referentes conceptuales centrales del proceso de investigación, como son la política educativa de lo cotidiano y la práctica pedagógica. En el segundo, se describe la metodología propuesta para la construcción y el análisis de los datos de la investigación. Después, se caracterizan las prácticas pedagógicas observadas y las establecidas en De Cero a Siempre, como base para la comprensión de la relación entre las prácticas pedagógicas institucionales de la educación inicial en Colombia y los lineamientos educativos de la política pública dirigida a la primera infancia colombiana. Finalmente, se señala cómo se desarrolla cotidianamente la política en las prácticas pedagógicas observadas de la modalidad institucional de educación inicial en Colombia.

\section{Referentes teóricos}

En la problemática que da sentido a la investigación se identifican dos conceptos centrales: el de política educativa, que se enmarca en la perspectiva de la política educativa de lo cotidiano, y el de práctica pedagógica, enmarcado en las perspectivas de práctica y arquitecturas de la práctica desarrolladas por Kemmis et al. (2014) y Kemmis \& Edward-Grooves (2018). En este apartado, se desarrollan los elementos teóricos esenciales para comprenderlos y para entender cómo se vinculan a la investigación.

En relación con el concepto de política educativa, este se deriva de la comprensión de la política pública como conjunto de orientaciones dadas por el Estado para responder a problemas sociales y políticamente construidos. Dichas respuestas dependen de las visiones, las representaciones, las percepciones y los intereses de los actores que forman parte del campo hacia el cual se dirigen (Cerna, 2013; Levinson et al., 2009; Roth-Deubel, 2017). En este sentido, la política pública es una práctica social que debe ser comprendida desde las formas de ver el mundo de los actores que participan en esta y desde los contextos en los que se inscribe: de ahí que su carácter es interpretativo, situado y no reproducible (Cerna, 2013; RothDeubel, 2014, 2017; Yanow, 2014; Baxter, 2016).

Conforme a lo anterior, las políticas educativas son el conjunto de orientaciones que establece el Estado que, si bien son una forma de acción política en la que este y el Gobierno tienen un papel privilegiado, movilizan diversos actores que son los encargados de atribuirle significado a las decisiones tomadas en las altas instancias de poder sobre la educación (Heras, 2015; Miñana-Blasco \& Arango-Vargas, 2011). Dicho conjunto de orientaciones trasciende a la normativa y se actualiza en las interacciones escolares y en la vida cotidiana de los actores educativos (Asprella, 2016). 
Las interacciones escolares son un lugar para entender cómo cualquier política pública educativa se actualiza. La política [educativa] no es una prescripción que se ejecuta o una norma que se implementa. En todo caso, es un proceso de construcción dinámico que hace actual lo que en algún momento se objetivó en prescripción (la ley, por ejemplo) y por tanto se hace acto en una serie de decisiones cotidianas por parte de diferentes actores educativos. (Heras, 2015, p. 7)

Tal comprensión de la política educativa plantea la necesidad de proponer nuevas categorías para analizar la realidad educativa, enraizada en la vida cotidiana de las escuelas y centrada en el vínculo que hay entre sujetos, "política y cotidianidad, más específicamente entre docentes, política educativa y cotidianidad de la escuela" (Vargas-González, 2020, p. 66). De lo anterior se deriva la perspectiva teórica sobre política educativa de lo cotidiano, para la cual la política educativa es lo que los sujetos e instituciones perciben, apropian e interpretan de lo objetivado en la norma, en el marco de un orden institucional ya existente, que se conjuga con unas tradiciones pedagógicas de la escuela. "Toda la experiencia escolar participa en esta dinámica entre las normas oficiales y la realidad cotidiana" (Rockwell, 2014, p. 14), y por lo tanto, no es posible incorporar la norma educativa oficial a la escuela tal y como fue formulada originalmente.

En conclusión, debido a que la acción política está sujeta a las contingencias de la vida diaria en las escuelas, el sentido de la política educativa se negocia en la vida social y se ubica en situaciones específicas; así, parte de lo que repercute en la escuela, en términos políticos es "lo que cada sujeto e institución interpretan desde sus condiciones de 'vida cotidiana'" (Asprella, 2016, p. 15). Lo anterior permite plantear la imposibilidad de un direccionamiento absoluto de las políticas educativas sobre las prácticas pedagógicas, pues el docente (en tanto actor del Estado) y los demás actores que conforman la comunidad educativa tienen un lugar de agenciamiento muy importante, porque se encargan de incorporar distintos elementos de las políticas educativas a sus intereses, modos de acción, recursos discursivos y formas de relacionarse (Grant-Lewis \& Naidoo, 2004).

En relación con el concepto de práctica pedagógica, este se deriva de la comprensión de la práctica como una acción moralmente comprometida, informada y orientada por las tradiciones de un campo específico, que apunta a la consecución de un fin (visión aristotélica). Dicha acción, que desde la visión de Marx y Hegel es humana, colectiva y hace historia, tiene consecuencias políticas, morales y sociales para las personas (Kemmis et al., 2014). Además, siempre responde a las circunstancias particulares en las que se da (es de naturaleza situada). De lo anterior se puede decir que 
la práctica pedagógica se configura a partir de "las condiciones de espacio y tiempo que le son particulares, es decir, [...] las condiciones históricas y materiales que existen en un lugar y en un momento dado, las cuales se materializan en los arreglos culturales-discursivos, materiales-económicos y socio-políticos" (Herrera \& Martínez, 2018, p. 22).

Para Kemmis et al. (2014) y Kemmis \& Edwars-Groves (2018), toda práctica pedagógica está compuesta por juegos del lenguaje (lo que se dice), actividades (lo que se hace) y relaciones (modos de relacionamiento), que se articulan alrededor de al menos un proyecto. Lo anterior devela un aspecto fundamental que hace que la labor pedagógica sea práctica: el proyecto, pues este es el que define su propósito. Adicionalmente, la práctica pedagógica configura y está configurada por lo que estos mismos autores denominan como las arquitecturas de la práctica, que son tres dimensiones paralelas o correlatos de lo que se dice, lo que se hace y los modos de relacionamiento, y cuya importancia radica en que la habilitan o la restringen. Dichas dimensiones son: los arreglos culturales-discursivos, o recursos que hacen posible que tanto los lenguajes como los discursos sean utilizados en y sobre la práctica pedagógica; los arreglos materiales-económicos, que hacen posibles las actividades desarrolladas durante la práctica pedagógica; $y$, finalmente, los arreglos socio-políticos, es decir, los instrumentos que hacen posible que las relaciones entre las personas y los objetos se den en la práctica pedagógica.

\section{Metodología de la investigación}

\section{Enfoque y diseño metodológico:}

\section{aproximación cualitativa y estudio de caso}

Para comprender la relación entre las prácticas pedagógicas de la modalidad institucional de la educación inicial en Colombia y los lineamientos educativos de la política pública dirigida a la primera infancia colombiana en el programa De Cero a Siempre, la investigación desarrollada se inscribió en un enfoque cualitativo-interpretativo (Denzin \& Lincoln, 2012) y hace énfasis en la naturaleza socialmente construida sobre las prácticas pedagógicas en la educación inicial, interpelando la idea de que existen prácticas pedagógicas objetivas y verdaderas, que actúan en correspondencia con unas normas universales y justas, estipuladas en la política educativa.

En ese sentido, este estudio tiene un gran potencial de transformación pedagógica, ya que se abre a la posibilidad de construir conocimiento de amplio alcance y contextualizado, que se produce de diversas maneras y, algunas veces, resulta incompleto y paradójico, como se puede apreciar en los resultados de la investigación (Dahlberg et al., 2005). 
Por otra parte, se utilizó un diseño de investigación emergente (Maxwell, citado por Bartlett \& Vavrus, 2017), que partió de una delimitación teórica sobre los conceptos de práctica pedagógica y política educativa de lo cotidiano, y que resultó esencial para reflexionar sobre cuál sería el tipo de investigación más pertinente para comprender la realidad educativa estudiada, y cuál el método de investigación más apropiado para desarrollar el proyecto. De esta forma se definió que se haría un estudio de caso comparativo (ECC), mediante el análisis de prácticas pedagógicas, basado en la teoría de las arquitecturas de la práctica (Kemmis et al., 2014), que se compone de dos momentos: observación de prácticas pedagógicas y conceptualización con el método derivado de la teoría fundamentada constructivista.

En cuanto al ECC, este se constituyó en una manera de "desatar" los proyectos, lo que se dice, lo que se hace, los modos de relacionamiento, y los recursos culturales-discursivos, materiales-económicos y socio-políticos presentes en la vida cotidiana de la labor pedagógica en educación inicial, observados a partir de la realización de descripciones ricas y detalladas de los mismos "por medio de un rastreo reiterativo y contingente de los actores, los factores y las características relevantes del objeto de estudio" (Bartlett \& Vavrus, citados por Vargas González, 2020, p. 84).

Ahora bien, tomando en cuenta que el estudio de caso es, principalmente, una elección sobre aquello que se ha de estudiar, es decir, sobre el caso, el referente esencial de este no son los métodos por los cuáles opera el caso, sino el caso como tal (Stake, 2013). De allí que los límites del caso no se establecieran a priori al proceso de investigación, sino que se construyeron a partir de los intereses, las hipótesis y las orientaciones teóricas, entre otras, que se fueron haciendo explícitas a medida que avanzó la investigación. Para este proyecto, el caso estudiado es el de las prácticas pedagógicas en la modalidad institucional de educación inicial en Colombia, y se seleccionó el método de análisis de prácticas pedagógicas basado en la teoría de las arquitecturas de la práctica por el potencial que tiene:

[...] para describir las interacciones y detectar en ellas las claves de contextualización que emplean los interactuantes para dar sentido a la acción colectiva propia y de otros. Para este tipo de análisis lo que se dice y el cómo se dice son indisociables, y, por ello, se presta especial atención a las formas "de decir y hacer" la acción. (Unamuno, 2015, p. 4)

\section{Los casos y los participantes de la investigación}

Tomando en cuenta que esta investigación se inscribe en campo de estudio de las prácticas pedagógicas, el análisis de las mismas basado en 
la teoría de las arquitecturas de la práctica fue el camino adecuado para comprender y conceptualizar dichas prácticas de la modalidad institucional de educación inicial en Colombia al re-imaginar, reconfigurar y reivindicar el trabajo pedagógico que realizan los docentes. Para el desarrollo del análisis mencionado, se observaron noventa prácticas pedagógicas de educación inicial en la modalidad institucional, distribuidas en siete municipios del país: Bogotá, Chía, Cogua, Guateque, Santa Marta, Ayapel y Medellín.

Figura 1.

Distribución geográfica de las instituciones educativas que participaron en la investigación

Nota: elaboración propia.

Los criterios de selección de las prácticas pedagógicas observadas fueron dos: en primer lugar, que las instituciones pertenecieran a Unidades de Servicio (UDS) que se rigen por los lineamientos del Instituto Colombiano de Bienestar Familiar (ICBF), es decir, la observación se limitó a prácticas pedagógicas de Centros de Desarrollo Infantil (CDI) y Hogares Infantiles (HI), porque estas entidades funcionan bajo parámetros similares y esto minimiza que existan variaciones entre ellas (Patton, citado por Bartlett \& Vavrus, 2017). En segundo lugar, que las docentes líderes de las prácticas pedagógicas participaran libre y voluntariamente en el proyecto de investigación. 
Para la selección de las UDS se utilizó un criterio de conveniencia, mas no de representatividad estadística, en la medida en que se invitaron a participar en la investigación CDI y HI que fueron referenciados por contactos personales de la investigadora principal y/o por agentes que trabajan en los mismos. Sin embargo, al momento de seleccionar las UDS en las que se llevó a cabo la observación, se buscó algún nivel de variedad en torno a tamaño de la institución, ubicación (rural o urbana) y fortalezas pedagógicas y de infraestructura. En total participaron nueve UDS y en cada una se observaron diez prácticas pedagógicas de la misma docente.

\section{Técnicas de producción de datos: inmersión en CDI y HI}

Recapitulando, el método de análisis de la labor pedagógica, basado en la teoría de las arquitecturas de la práctica, se compuso de dos momentos: uno de observación y otro de conceptualización. En cuanto al primero, este contribuyó a la construcción de un relato completo y complejo sobre lo que se dice, lo que se hace y los modos de relacionamiento en las prácticas pedagógicas observadas, concentrando la mirada en los elementos de la vida cotidiana que hacen parte de las mismas, sin valorarlas de cara a qué tanto se ajustan o no a los lineamientos del Estado y sin definir su calidad (Angrosino, 2015).

Este momento inició con la delimitación de la práctica a observar, pues en una jornada diaria de las UDS los niños y las docentes participan de diversos momentos "soportados" en intencionalidades pedagógicas (el de la bienvenida, el de alimentación, el de la estrategia pedagógica central, entre otros), pero, como no es posible registrarlos y analizarlos todos (noventa jornadas), se definió que la estrategia pedagógica central era el momento más adecuado para el análisis, ya que en esta lo que se dice, lo que se hace y los modos de relacionamiento se articulan alrededor de un propósito claramente declarado en torno a la enseñanza y al aprendizaje de un saber.

\section{Análisis de datos: método de comparación constante constructivista}

Una vez se observaron y registraron en video las 90 prácticas pedagógicas, se seleccionaron 36 (4 por cada una de las docentes observadas, tabla 1), para registrarlas (individualmente) en el instrumento de transcripción propuesto por Kemmis et al. (2014), y posteriormente analizarlas en otro modelo propuesto por los mismos autores, basado en los siguientes elementos: propósito, lugar, lo que se dice, lo que se hace, los modos de relacionamiento, los arreglos culturales-discursivos, los arreglos materiales económicos, los arreglos socio-políticos, las disposiciones y las tradiciones. 
Tabla 1

Identificación de prácticas pedagógicas observadas en la modalidad institucional

\begin{tabular}{|c|c|c|c|c|}
\hline Docente & $\mathbf{N}^{\circ}$ & Fecha & Nombre de la práctica & Duración \\
\hline \multirow{4}{*}{ D1 } & Obs. 1 & Febrero 13, 2018 & Partes del cuerpo & $54: 42 \min$. \\
\hline & Obs. 2 & Febrero 28, 2018 & Canto y baile & $58: 53 \mathrm{~min}$. \\
\hline & Obs. 3 & Marzo 5, 2018 & Bandera de Colombia & $34: 08 \mathrm{~min}$. \\
\hline & Obs. 4 & Marzo 23, 2018 & Trabajo colaborativo & $35: 50 \mathrm{~min}$. \\
\hline \multirow{4}{*}{ D2 } & Obs. 5 & Mayo 17, 2018 & Bosque encantado & 22:35 min. \\
\hline & Obs. 6 & Mayo 22, 2018 & Culturas (colectiva) & $38: 51 \mathrm{~min}$. \\
\hline & Obs. 7 & Mayo 23, 2018 & Sentimientos & 26:49 min. \\
\hline & Obs. 8 & Mayo 28, 2018 & Visita a la biblioteca & $42: 59$ min. \\
\hline \multirow{4}{*}{ D3 } & Obs. 9 & Junio 13, 2018 & Narración del miedo & 29:26 min. \\
\hline & Obs. 10 & Junio 14, 2018 & Luna, luna, luna, sol & 25:35 min. \\
\hline & Obs. 11 & Junio 19, 2018 & Instrumento familiar & 20:19 min. \\
\hline & Obs. 12 & Junio 22, 2018 & Dónde guardar los cubiertos & $44: 52 \mathrm{~min}$. \\
\hline \multirow{4}{*}{ D4 } & Obs. 13 & Junio 28, 2018 & Aros & 29:46 min. \\
\hline & Obs. 14 & Julio 11, 2018 & Dramatización: Caperucita Roja & 18:31 min. \\
\hline & Obs. 15 & Julio 12, 2018 & Pintura por grupos & $32: 00 \mathrm{~min}$. \\
\hline & Obs. 16 & Julio 13, 2018 & Lectura de cuento: No, no, no & 20:08 min. \\
\hline \multirow{4}{*}{ D5 } & Obs. 17 & Agosto 2, 2018 & Exposición mascotas & 48:57 min. \\
\hline & Obs. 18 & Agosto 3, 2018 & Reciclaje (colectiva) & $44: 51 \mathrm{~min}$. \\
\hline & Obs. 19 & Agosto 9, 2018 & Lactancia materna (padres) & 19:01 min. \\
\hline & Obs. 20 & Agosto 10, 2018 & Lectura: Cuento animales & 21:34 min. \\
\hline \multirow{4}{*}{ D6 } & Obs. 21 & Agosto 16, 2018 & Lectura: Caperucita Roja & 36:58 $\min$. \\
\hline & Obs. 22 & Agosto 23, 2018 & Poema al planeta tierra & $34: 03 \mathrm{~min}$. \\
\hline & Obs. 23 & Agosto 29, 2018 & Puntos cardinales & $61: 42 \mathrm{~min}$. \\
\hline & Obs. 24 & Agosto 30, 2018 & Títeres & $48: 20 \mathrm{~min}$. \\
\hline \multirow{4}{*}{ D7 } & Obs. 25 & Septiembre 4, 2018 & Escritura & 45:00 min. \\
\hline & Obs. 26 & Septiembre 7, 2018 & Asamblea inicial & $18: 12 \mathrm{~min}$. \\
\hline & Obs. 27 & Septiembre 13, 2018 & Velocidad & $51: 42 \min$. \\
\hline & Obs. 28 & Septiembre 14, 2018 & Maqueta & $51: 54$ min. \\
\hline \multirow{4}{*}{ D8 } & Obs. 29 & Septiembre 25, 2018 & Recortar números & $31: 25$ min. \\
\hline & Obs. 30 & Septiembre 26, 2018 & Dibujar en hojas & 39:15 min. \\
\hline & Obs. 31 & Septiembre 27, 2018 & Rotulación de colores & 43:51 min. \\
\hline & Obs. 32 & Octubre 2, 2018 & Números & 27:17 min. \\
\hline \multirow{4}{*}{ D9 } & Obs. 33 & Octubre 12, 2018 & Cuento: Niña Bonita & $21: 58 \mathrm{~min}$. \\
\hline & Obs. 34 & Octubre 16, 2018 & Camino al hormiguero & $31: 37$ min. \\
\hline & Obs. 35 & Octubre 18, 2018 & Cuento: Antes, ahora, después & 16:03 min. \\
\hline & Obs. 36 & Octubre 19, 2018 & Cuento: Un corazón que late & $38: 00 \mathrm{~min}$. \\
\hline
\end{tabular}

Nota: Elaboración propia

No obstante, al pasar directamente del instrumento de registro al de análisis, se desperdiciaba gran parte de la riqueza y del nivel de detalle que portaban las transcripciones, al tiempo que no se estaban encontrando 
elementos cualitativamente diferentes a los identificados durante las observaciones de campo. Por tal motivo, se decidió llevar a cabo un proceso de categorización de los 36 registros de las prácticas pedagógicas con el método de comparación constante propuesto por la teoría fundamentada constructivista, el cual permitió darle continuidad a la metodología de Kemmis et al. (2014), para entender cómo se entraman los sujetos, los objetos y las situaciones que van construyendo las prácticas pedagógicas en contexto, en la vida cotidiana, y en clave de lo relacional (Charmaz, 2013; 2017).

Tal proceso de categorización inició con la codificación abierta, renglón por renglón, de las transcripciones de las prácticas pedagógicas seleccionadas, para definir lo que se dice, lo que se hace y los modos de relacionamiento. Sin embargo, a medida que se iba avanzando en esta sistematización, se hizo evidente la imposibilidad de construir códigos abiertos sobre los modos de relacionamiento, porque estos no son explícitos en las transcripciones; entonces, se tomó la decisión de llevar a cabo solo la codificación sobre lo que se dice y lo que se hace e inferir los modos de relacionamiento en un nivel de análisis un poco menos abstracto durante la codificación axial.

Del primer ejercicio de codificación abierta se construyeron 96 códigos (45 de lo que se dice y 51 de lo que se hace) con su respectiva definición. Posteriormente, se realizó un proceso de reducción de códigos abiertos, al refundir los códigos de 4 o menos referencias en otros, y fusionar códigos con sentidos análogos, hasta llegar a un total de 27; una vez se contó con los códigos abiertos finales, revisados y densamente descritos, se dio paso a la codificación axial, que consistió en agruparlos de acuerdo a sus sentidos, es decir, el criterio de agrupación ya no era si el código se refería a lo que se dice o lo que se hace, sino al sentido que le subyace.

La codificación axial llevó a construir ocho familias de códigos o categorías, que implícitamente daban cuenta de modos de relacionamiento entre los niños con sus pares y con las docentes. Luego de un proceso de revisión, subordinación y reorganización de las categorías, se definieron las cuatro jerarquías finales por medio de las cuales se describen las prácticas pedagógicas observadas, y que develan los principales sentidos u objetivos de estas, los cuales son: enseñar un saber que las docentes poseen, fortalecer la participación de los niños en sus procesos de aprendizaje, definir y regular los momentos y las transiciones de la práctica, y mantener la disciplina individual y grupal en la práctica.

Cabe destacar que el momento de codificación axial incorporó el análisis de fuentes documentales, que representan "los fundamentos teóricos y epistemológicos, las perspectivas sobre educación inicial y las rutas de 
acción que subyacen a la propuesta educativa para la primera infancia en Colombia" (Vargas-González, 2020, p. 206). Dicho análisis se construyó a partir de la lectura, la categorización de las bases curriculares para la educación inicial y preescolar (MEN, 2017) y los referentes técnicos para la educación inicial, como guías para tener una idea clara sobre cuáles son las prácticas pedagógicas de educación inicial, en la modalidad institucional, que el Estado colombiano espera ver operando.

Finalmente, se dio paso al proceso de codificación selectiva, que consistió en identificar las relaciones entre las categorías definidas. Sobre dichas relaciones, a nivel general, se encontró que al interior de las prácticas pedagógicas observadas hay una ecología entre los proyectos que las fundamentan, lo cual quiere decir que, aunque algunas veces unos prevalecen sobre los otros, otras veces se superponen y otras más se complementan, pero, en general, todos están presentes en las prácticas pedagógicas. Asimismo, se identificó que dos proyectos se orientaron más hacia la enseñanza, mientras que otro estaba más del lado de la organización de la práctica y, finalmente, el último estaba más del lado de la formación de los niños en tanto sujetos sociales; no obstante, todos estaban al servicio de lo pedagógico.

La codificación selectiva involucró a las participantes del trabajo de campo en el desarrollo de dos grupos de discusión (uno con las docentes, cuyas prácticas pedagógicas fueron observadas, y otro con coordinadores de las UDS), en los cuales se puso a disposición de los actores la sistematización realizada sobre sus prácticas (Gandulfo, 2015), con el objetivo de que ellos, con sus inquietudes y aportes, ayudaran a entender mejor las relaciones, tanto entre las categorías de análisis, como en la relación entre sus prácticas pedagógicas y los planteamientos educativos en De Cero a Siempre

A manera de reflexión final sobre el diseño metodológico presentado, es importante señalar que este permitió la vigilancia epistemológica a lo largo de la investigación, por medio de la cual fue posible identificar las siguientes limitaciones del estudio: i) existen, en el hacer de las docentes observadas, otros momentos constituidos por lenguajes, acciones y modos de relacionarse que no se registraron en este análisis y, por lo tanto, quedaron fuera del trabajo; ii) los análisis están focalizados en gran medida en la enseñanza y en las docentes debido a que los intereses y caminos profesionales de la investigadora determinaron el curso de los mismos, por tal motivo no se profundizó en los procesos de aprendizaje de los niños; y iii) algunos de los elementos que constituyen las prácticas pedagógicas de educación inicial no pasan por el lenguaje hablado, en consecuencia, no fue posible captar su esencia en los instrumentos de trascripción utilizados. 


\section{Resultados y discusión}

Para establecer la relación entre las prácticas pedagógicas de la modalidad institucional de la educación inicial en Colombia y los lineamientos educativos de la política pública dirigida a la primera infancia colombiana en el programa De Cero a Siempre, fue necesario traducir las prácticas pedagógicas prescritas en la política pública y las observadas en CDI y HI en términos de lo que se dice, lo que se hace y los modos de relacionamiento que las caracterizan, junto con los respectivos enfoques culturales-discursivos, materiales-económicos y socio-políticos que las habilitan (perspectiva teórica de las arquitecturas de la práctica). En este apartado se presentan dichas caracterizaciones y, posteriormente, se aclara cómo se comprendió la relación mencionada.

\section{Las prácticas pedagógicas de la política}

\section{De Cero a Siempre: el deber ser pedagógico}

El análisis documental del componente educativo de De Cero a Siempre revela que lo que le da especificidad a la educación inicial en esta política pública es el reconocimiento de las características, las capacidades y las habilidades singulares de los niños, como fundamento para proponer y desarrollar procesos educativos estructurados, planeados y sistemáticos, que los orienten hacia la construcción de aprendizajes significativos. Los procesos educativos estructurados indican que las acciones se realizan con la intencionalidad de incidir en el desarrollo integral de los niños; en cuanto a planeación, significa que hay unos propósitos que orientan dichas acciones (los cuales requieren definir unos medios, unos recursos, unas estrategias y unas actividades); y son sistemáticos, puesto que señalan que la educación inicial se organiza de cara a las preguntas, los intereses, los saberes y las formas de ser y de actuar de los niños en el mundo.

Es por ello que, en las prácticas pedagógicas de la modalidad institucional de educación inicial prescritas en De Cero a Siempre (MEN, 2017; 2014c) se espera que los niños planteen ideas, significados, hipótesis, inferencias y soluciones a problemas, mediante recursos culturales-discursivos como preguntas y respuestas sobre lo que no saben; en este sentido, les corresponde a los docentes plantear preguntas cuyas respuestas son esencialmente abiertas y no predeterminadas, compartir ideas, escuchar a los niños e incentivar la lectura, la escritura, la creación de historias, cantar y asociar (MEN, 2017; 2014a; 2014d).

En cuanto a lo que se hace, De Cero a Siempre prescribe unas acciones que atañen a los docentes y unas acciones que atañen a los niños. Sobre las acciones que atañen a los docentes, se espera que ellos escriban formatos 
de planeación y de reflexión sobre la práctica pedagógica, y que observen a los niños para conocerlos y promover su desarrollo (MEN, 2017; 2014e). Sobre las acciones que atañen a los niños, se espera que ellos observen, exploren, manipulen y se desplacen por el medio (MEN, 2017). Por otra parte, los arreglos materiales-económicos (recursos) que habilitan las acciones señaladas son: para los docentes, diseñar la práctica pedagógica (planear), preparar y disponer sus materiales (MEN, 2017; 2014c; 2014f); y para los niños, el juego, el arte, la literatura y la exploración del medio, básicamente los cuatro campos de experiencia que estructuran la propuesta educativa de este programa (MEN, 2014a; 2014b; 2014c; 2014e).

Como se puede inferir, para la política educativa dirigida a la primera infancia colombiana planear, estructurar, organizar y decidir sobre la práctica pedagógica es una responsabilidad exclusiva de los docentes; además, toman como base sus comprensiones de las necesidades e intereses de los niños.

Por último, en las prácticas pedagógicas de educación inicial en la modalidad institucional prescritas en De Cero a Siempre, se espera que los modos de relacionamiento entre los docentes y los niños, y de los niños con sus pares, estén basados en el trabajo colaborativo, el cuidado y la atención a las necesidades e intereses de los niños (MEN 2017; 2014c; 2014d; 2014f; 2014g). En cuanto a los arreglos socio-políticos (recursos) prescritos para que habiliten los modos de relacionamiento mencionados, algunos tienden hacia el ejercicio del poder de los docentes sobre los niños, en la medida que ellos deben prestar atención a los niños para definir cuáles son sus intereses, y planear cómo potenciar sus desarrollos (MEN, 2017). En cambio, hay otros arreglos socio-políticos que tienden hacia la solidaridad, como son compartir, llegar a acuerdos y acompañarse mutuamente en la práctica pedagógica (MEN, 2014b).

\section{Las prácticas pedagógicas cotidianas en la modalidad institucional de educación inicial en Colombia}

En las prácticas pedagógicas de educación inicial en la modalidad institucional observadas, quienes ostentan la mayor parte de lo que se dice son las docentes. Ellas enseñan saberes a los niños (proyecto de la práctica), presentando contenidos o dando explicaciones, y para ello los arreglos culturales-discursivos (los recursos) más recurrentes, que habilitan eso que se dice, son:

i) La exposición, que se caracteriza porque las docentes van brindando información a los niños sobre un tema específico, tal y como sucede en el siguiente ejemplo: 
Docente: hoy vamos a ver la bandera de Colombia, que es un símbolo patrio. Niño hombre: ¿la bandera de Colombia?

Docente: la bandera de Colombia, ¿qué colores tiene?

Coro: amarillo, azul...

Docente: amarillo, ¿qué significa el amarillo?... como la camisa que traes hoy... El amarillo significa la riqueza; el azul, los ríos y el cielo, y el rojo, la sangre derramada. (Obs. 3, marzo 5, 2018)

ii) Las preguntas cuyas respuestas están predeterminadas. Cuando las docentes hacen preguntas a los niños que tienen una única respuesta acertada, y ellos se encargan de decir la respuesta esperada:

Docente: alguien sabe ¿qué es esto?, ¿qué es esto?

Niño hombre: una taza.

Docente: ¿una qué?

Niño hombre: una taza.

Docente: ¿qué es? [...] mira, ella sí sabe, Salo, ¿qué es?

Niña mujer: cucharas.

Docente: ¿qué?... para las cucharas... bravo, Salo, bravo, bravo, bravo, bravísimo. (Obs. 12, junio 22, 2018)

iii) La repetición, caracterizada porque las docentes les piden a los niños que digan varias veces un contenido expuesto como parte de su afianzamiento, como se puede apreciar en el siguiente ejemplo:

Docente: eso, muy bien, ¿cómo se llama este?

Niña mujer: rectángulo.

Docente: eso, muy bien...

Docente y coro: rectángulo.

Docente: ¿cómo se llama?

Niña mujer: rectángulo.

Docente: ¿cómo se llama esta figura?

Niña mujer: rectángulo.

Docente: eso, muy bien. (Obs. 25, septiembre 4, 2018)

iv) La instrucción, que se caracteriza porque las docentes les dicen a los niños cómo hacer un producto o ejercitar una habilidad, por ejemplo:

Separamos un poquito las piernas, separamos un poquito las piernas... a ver, todos aquí, atentos; separamos un poquito las piernas y vamos a hacer esto (movimientos circulares con la cadera). Todos dentro del aro, eso. (obs. 13, junio 28, 2018) 
También, la profe da un papel a cada uno:

iMiren lo que vamos a hacer! vamos a hacer el camino [...] y le vamos a ir pegando aquí todo el camino a las hormiguitas, ¿listo?, con colbón; vamos a rasgar el papel y vamos a hacer bolitas, y vamos a pegar el camino de las hormiguitas que no sabían por dónde irse, ¿listo? (Obs. 34, octubre $16,2018)$

En algunas ocasiones, y con muy poca ocurrencia, cuando el proyecto de la práctica pedagógica es "fortalecer la participación de los niños en sus procesos de aprendizaje", ellos presentan sus opiniones e hipótesis, entre otros, sin tanta directividad o intervención por parte de las docentes. Los arreglos culturales-discursivos (los recursos) que los habilitan para hacer lo antes mencionado están mediados por el lenguaje escrito y por el trabajo en torno a la literatura. Esto se dio, por ejemplo, cuando en una de las prácticas pedagógicas (obs. 35) los niños propusieron el final para un cuento y la docente lo plasmó en un texto escrito visible para todos, sin hacerle ninguna modificación; en otra práctica pedagógica, algunos niños contaron, a través de las imágenes de libro, un cuento a sus compañeros:

Niña mujer: ihola, amiguitos!

Coro: ihola!

Niña mujer: ¿cómo están?

Coro: ibien!

Docente: idiles qué les vas a contar!

Niña mujer: ¿qué les voy a contar?

Docente: idiles qué les vas a contar!

Niña mujer: mi papá está tomando chocolate.

Niño hombre: ja, ja, ja...

Niña mujer: Mi papá no le tiene miedo al lobo feroz.

Niña mujer: y después se subió a donde se lava la ropa.

Niña mujer: y después saltó.

Niña mujer: el papá era fuerte, mi papá es fuerte. [...] Mi papá era fuerte y muy inteligente. Y se ganó 1, 2 [...]. El papá se convirtió en caballo, se convirtió como en un gorila y como un hipopótamo. [...] Era un osito, pero se convirtió como un papá. El papá se convirtió como un profesor y después se convirtió en un cabello de escoba. Y después bailaba. [...] Y después bailaba. Y bailaba y decía: "iOh, gloria inmarcesible! [...] iOh, júbilo inmortal!, en surcos de dolores, el bien germina ya, el bien germina ya. iOh gloria inmarcesible!, ioh júbilo inmortal!". Y después el papá jugaba futbol, y después sonreía, y después le decía al hijo: "te quiero mucho". Y colorín colorado, este cuento se ha acabado. iGracias!

Docente: imuy bien! Un aplauso. Bravo, muy bien.

Coro: ibravo! (obs. 24, agosto 30, 2018) 
Por su parte, en las prácticas pedagógicas de educación inicial que fueron observadas en la modalidad institucional, lo que más hacen los niños son productos tangibles derivados de los contenidos expuestos por las docentes.

Figura 2.

Producto: esqueleto humano con sus partes correctamente ensambladas

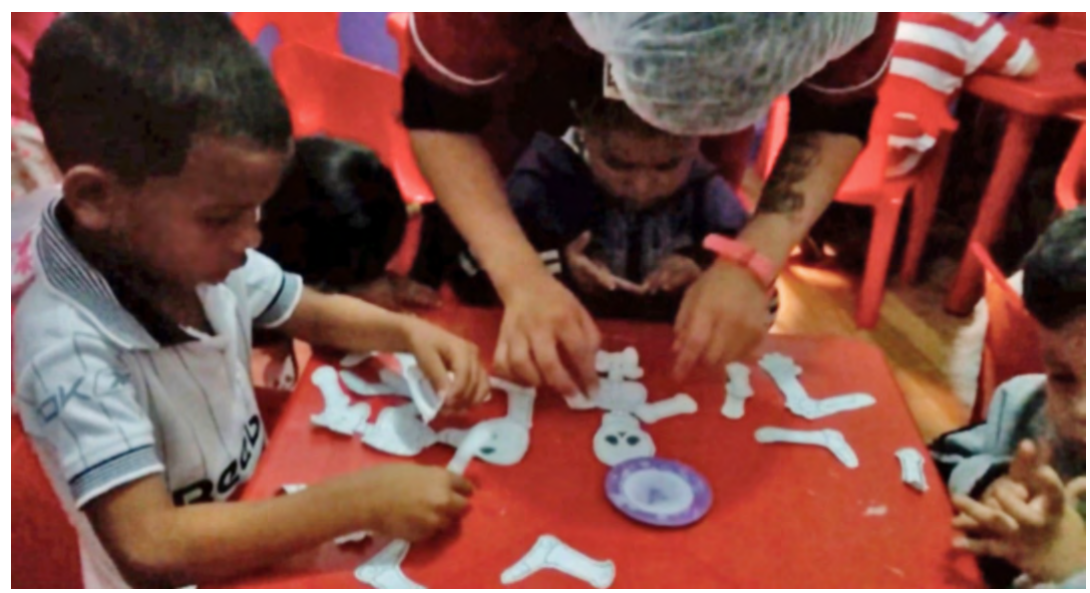

Nota: (Obs. 1, febrero 13 de 2018).

Los arreglos materiales-económicos (los recursos) que habilitan eso que hacen los niños, lo proponen y agencian las docentes, tales como: seleccionar y disponer los materiales con los que los niños van a trabajar (figura 3), organizar el lugar de la práctica pedagógica (figura 4), ubicar a los niños en el espacio físico de la práctica -lo que implícitamente les indica las acciones que deben hacer a lo largo de la misma- (figura 5), definir los tiempos para desarrollar cada acción y modelar las acciones que van a realizar los niños (figura 6).

Figura 3.

Actividad con aros para el desarrollo motriz

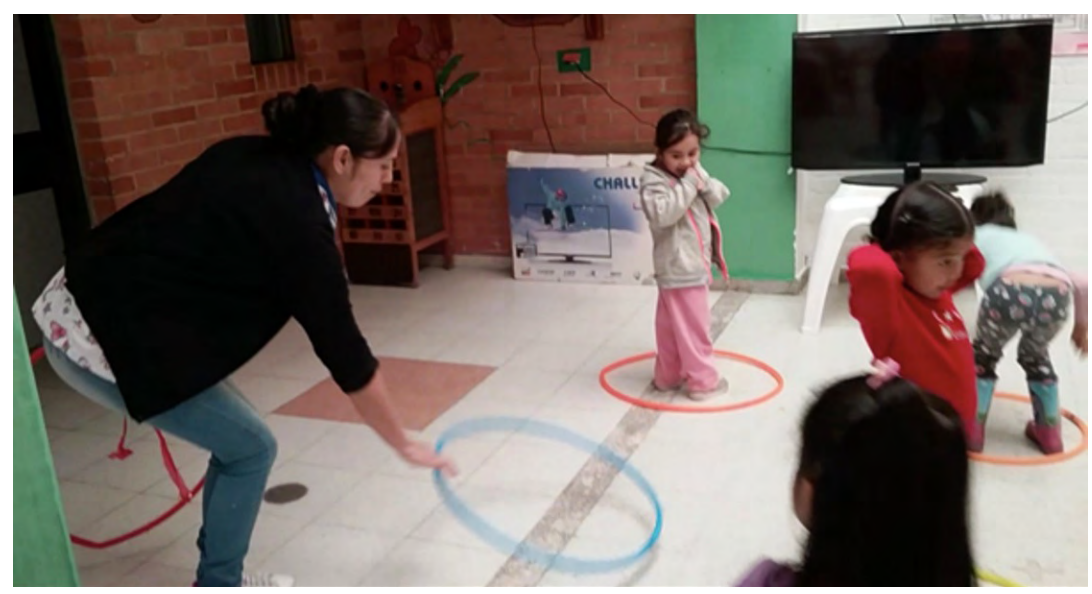

Nota: (Obs. 13, junio 28 de 2018). 
Figura 4.

Preparación del espacio para actividad de escritura

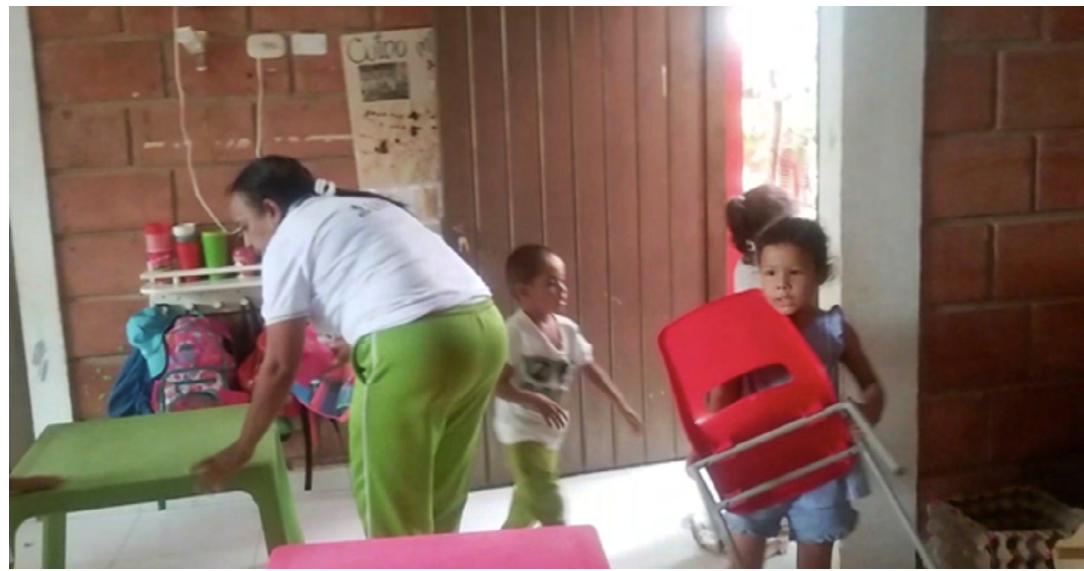

Nota: (Obs. 23, agosto 29 de 2018).

Figura 6.

Actividad de rasgado

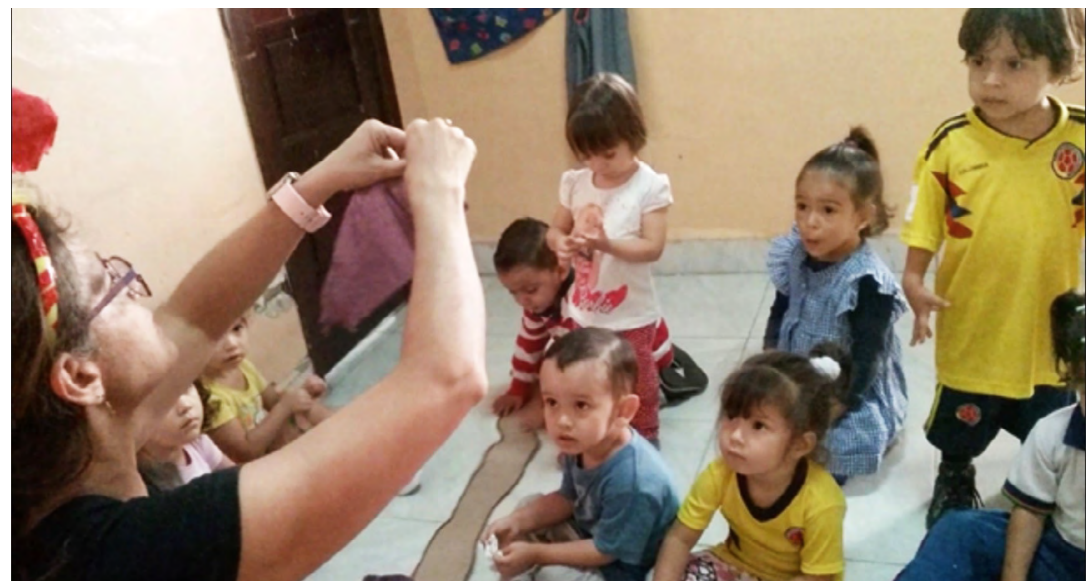

Nota: (Obs. 34, octubre 16 de 2018). 
Dichos recursos son el correlato y reproducen, al mismo tiempo, lo que hacen las docentes, es decir: planear de cara a los objetivos de la práctica pedagógica y organizar el lugar de la misma manera, cuando el proyecto que se persigue es "definir y regular los momentos y las transiciones de la práctica", además de controlar los impulsos y los movimientos de los niños durante la práctica, el proyecto que se persigue es "mantener la disciplina individual y grupal en la práctica".

Finalmente, en cuanto a los modos de relacionamiento que se configuran en las prácticas pedagógicas cotidianas de educación inicial, en la modalidad institucional, los más recurrentes están fundamentados en la trasmisión de saberes e imposición de comportamientos para "mantener la disciplina individual y grupal en la práctica".

Por su parte, los arreglos socio-políticos (los recursos) que utilizan las docentes están mediados por el poder que ejercen sobre los niños, es decir: i) definen qué pueden aprender, ellas seleccionan en solitario los contenidos y saberes que se abordan en las prácticas pedagógicas; ii) eligen los productos que van a realizar los niños en el proceso de aprendizaje; iii) imponen comportamientos y límites a los cuerpos de los niños, tales como: permanecer sentados: "Guillermo, siéntate [...]. iSiéntate! iSiéntate! iSiéntate que vamos a armar!" (obs. 1, febrero 13, 2018), o permanecer callados: "Vamos a cerrar los brazos así, y vamos a estar callados un minuto mientras yo los voy colocando en línea recta" (obs. 8, mayo 28, 2018); iv) deciden qué, de lo que dicen y hacen los niños, es acertado o no: "tú lo hiciste mal, no escuchaste [...] Me hubieras dicho que te cambiara de pincel" (obs. 3, marzo 5, 2018); y v) sancionan determinados comportamientos:

Docente: ihuy!, esa Ivón... iDios mío, dame la paciencia! iPárese de ahí, Ivón! iYa no más, ya no más! iCamine para el baño le lavo esas manos, porque usted no sigue instrucciones! iLe dije clarito que la ropa no, y eso fue lo primero que hizo! (obs. 15, julio 12, 2018).

Docente: ...Muy delgado, ¿ven?, pero miren una cosa muy diferente... iJuan Pablo, escúchame! Miren algo que a mí me tiene sorprendida, Elimelec... iJuan Pablo, vete para allá, vamos y nos sentamos allá! (obs. 27, septiembre 13, 2018).

Sin embargo, algunas veces (muy pocas) se dan unos modos de relacionamiento que dan espacio a que los niños se sientan seguros de participar, para los cuales, los arreglos socio-políticos (los recursos) que los habilitan generan ambientes en los que: i) se reconoce la importancia de la voz propia y de la del otro, y donde generalmente, en estos, las docentes velan porque todas las voces sean escuchadas: "pero, mi amor, es que 
estamos leyendo y a ti te oyeron todos tus compañeritos. Te oyeron, y tú no estás oyendo a tus compañeros. iSiéntate bien! Y ahorita vamos a jugar, ¿listo?" (obs. 21, agosto 16, 2018), y ii) los niños tienen la posibilidad de expresar sus ideas sin que estas sean clasificadas como buenas o malas, según el criterio del adulto, por ejemplo:

Docente: ¿cómo se llamará este cuento?

Coro: La leche materna.

Niña mujer: ese cuento se llama: la leche materna, cuando cuida a un bebé y se alimenta.

Docente: bueno, ya habló Miguel Ángel... Valentina.

Niña mujer: La materna que cuida.

Docente: La materna que cuida. ¿quién más quiere saber cómo se llama este cuento?

Niña mujer: La leche materna del bebé cuando se alimenta.

Docente: La leche materna con la que se alimentan. Nicol...

Niño hombre: El del corazón.

[...]

Niña mujer: Porque le da la leche materna.

Docente: Porque le da la leche materna... Este cuento se llama: Un corazón... Un corazón que late. Lo escribió, lo escribieron dos personas: Joelle Jilivet y Virginie Aladjidi. (obs. 36, octubre 19, 2018)

\section{Las prácticas pedagógicas observadas y su relación con las prácticas pedagógicas en De Cero a Siempre: horizontes compartidos, complementariedades, contradicciones y ausencias}

La caracterización de las prácticas pedagógicas en la modalidad institucional de la educación inicial colombiana, establecidas en la política pública, permiten comprender, de un lado, la política educativa de lo cotidiano dirigida a la primera infancia en Colombia, representada en las prácticas pedagógicas de educación inicial observadas, y, de otro, la política educativa normativa dirigida a la primera infancia en Colombia, contenida en los documentos educativos de De Cero a Siempre. De esta manera, se planteó la tesis que da respuesta a la problemática que enmarca el proceso de investigación desarrollado a lo largo del artículo.

Fue posible comprender la relación entre la política educativa de lo cotidiano, dirigida a la primera infancia en Colombia, y la política educativa normativa, dirigida a esta misma población, a partir de cuatro elementos: los horizontes compartidos, las complementariedades, las contradicciones y las ausencias. Sobre los horizontes compartidos, en las prácticas pedagógicas prescritas en De Cero a Siempre y observadas en CDI y HI se busca: i) promover el desarrollo y el aprendizaje de los niños; ii) la expresión segura 
por parte de los niños, aunque en la política educativa en las prácticas observadas en CDI y HI esto todavía es muy incipiente, haciéndose tangible en algunas intencionalidades de las docentes, pero generalmente se desdibuja al pasar de la intencionalidad a la acción; y iii) establecer relaciones de cuidado, reconocimiento y respeto, asunto que en la política educativa, dentro de las prácticas observadas en CDI y HI también se presenta en algunas intencionalidades de las docentes, pero se distorsiona con mucha frecuencia en la acción.

Adicionalmente, en cuanto a los horizontes compartidos tanto para la política educativa de lo cotidiano como para la política educativa normativa, dirigida a la primera infancia en Colombia, planear y organizar la práctica pedagógica es una responsabilidad casi exclusiva de los docentes. En ese orden de ideas, ellos son los encargados de definir qué se va a hacer, cómo se va a hacer, dónde se van a ubicar los niños y con qué compañeros, y los materiales con los que van a interactuar, entre otros. Pero más importante aún es que los docentes son los encargados de identificar cuáles son los intereses y las necesidades de los niños, lo que debilita las posibilidades de agencia de los últimos.

Sobre las complementariedades, la política educativa en las prácticas pedagógicas observadas en CDI y HI complementa los ideales expresados en la política educativa prescrita en De Cero a Siempre y define cuáles son esos comportamientos socialmente aceptados en un aula de educación inicial de la modalidad institucional, de allí que haya un marcado énfasis en sancionar y hacer esfuerzos para que los niños aprendan a convivir y a resolver situaciones propias de la vida en la escuela; para De Cero a Siempre, estos dos aprendizajes quedan en un plano general de la vida social. Por su parte, los ideales expresados en la política educativa en este programa complementan la política educativa de las prácticas pedagógicas observadas en $\mathrm{CDI}$ y $\mathrm{HI}$, haciendo énfasis sobre la necesidad de llevar un registro sistemático de la observación y acompañamiento de los niños, reconociendo que el arte y la exploración del medio son campos de experiencia fundamentales para potenciar sus aprendizajes; en las prácticas pedagógicas observadas, el único campo de experiencia que se hace tangible es la literatura.

En la política educativa de las prácticas pedagógicas observadas en CDI y HI, se identifican tres asuntos que van en contravía de los ideales expuestos en la política educativa prescrita en De Cero a Siempre: i) la sanción y la imposición como mecanismos para disciplinar a los niños, y para controlar sus comportamientos y reacciones cuando no son acordes a los que las docentes esperan; ii) existe una tendencia de que los niños apropien contenidos por medio de la repetición, en detrimento de la posibilidad de que 
ellos exploren y actúen sobre el mundo para construir sus conocimientos propios; y iii) las preguntas que se hacen en la mayoría de prácticas pedagógicas observadas son cerradas y tienen respuestas específicas, pues la docente espera que el niño responda lo que ella quiere, lo cual impide que "el niño se cuestione sobre lo que no sabe, lo que le inquieta o lo que quiere profundizar" (Vargas-González, 2020, p. 238).

Finalmente, gracias al análisis realizado fue posible comprender que la política educativa prescrita en De Cero a Siempre le da poca importancia al rol del docente, a pesar de que a este se le atribuyen múltiples responsabilidades sobre la organización, el mantenimiento de la práctica pedagógica y la enseñanza como proceso fundamental de todo acto educativo. Por su parte, la política educativa en las prácticas observadas en CDI y HI no mostró espacios en los que las docentes reflexionaran sobre lo que hicieron en el día a día, o sobre las decisiones que tomaron (aunque esto no quiere decir que no existan, puede que dichos espacios sucedieran en momentos de las jornadas que no fueron registrados). De igual forma, las actividades y los arreglos materiales-económicos dirigidos a los niños quedaron supeditados a las actividades y arreglos materiales-económicos dirigidos a las docentes.

Las ausencias señaladas ponen de manifiesto que, cuando la enseñanza se asume más como una acción técnica, y en consecuencia al docente se le despoja de protagonismo en los procesos educativos, los horizontes que comparten la política educativa de lo cotidiano con la política educativa normativa se materializan de maneras muy diferentes. Si los docentes no tienen claro qué, cómo, cuándo y para qué enseñar (asuntos que trascienden la habilidad técnica y pasan necesariamente por la reflexión pedagógica), optan por repetir patrones de enseñanza que han observado o vivido muchos de ellos, que reproducen las contradicciones presentadas. En otras palabras, y en voz de uno de los actores de la investigación:

Entonces, en algunos momentos uno llega a sentirse sin herramientas, porque lo que uno ha construido desde la experiencia, lo que uno sabe desde su conocimiento, sea como técnico, madre comunitaria o licenciada profesional, no le dio para más. Estamos ahí sin recibir constantemente formación, si bien la educación también avanza, los niños son distintos, las generaciones son distintas y probablemente la estrategia que a mí me funcionó hace diez años con una generación de 1999 no es la misma. (Grupo de discusión de docentes, septiembre 18, 2019)

Así pues, contar con unos fundamentos técnicos y curriculares no reemplaza la reflexión pedagógica; por tal motivo, trabajar sobre las ausencias expuestas abre la posibilidad de fortalecer la reflexión en torno a las prácticas pedagógicas de educación inicial en la modalidad institucional, 
para promover en los docentes "la toma de decisiones sopesadas e informadas por su[s] saber[es] como profesional[es], acordes con las características del contexto y con las situaciones que se van dando en el día a día" (Vargas-González, 2020, p. 240), de tal suerte que se abran a la posibilidad de que resulten maneras de enseñar distintas a las que conocen, que muchas veces experimentaron como estudiantes, y que requieren de su ingenio y creatividad para ser configuradas.

Esto es muy potente porque libera a los docentes de la "expectativa" de cumplir múltiples obligaciones al mismo tiempo, y al pie de la letra; a la vez que pone de manifiesto [...] que lo que se propone en la normativa no siempre se materializa en el aula ni que cuando lo hace es igual a cómo fue previsto. (p. 241)

\section{Conclusiones}

El camino recorrido hizo cada vez más clara la dimensión de lo cotidiano de la política educativa dirigida a la primera infancia en Colombia en la modalidad institucional, la cual tiene que ver con el cómo las docentes y los niños crearon y recrearon, en el día a día, ese horizonte trazado por los lineamientos educativos del programa. De allí que lo que se declara en la normativa sobre lo que se espera de las prácticas pedagógicas pasa inevitablemente por la lectura, la selección, el recorte, la abstracción, la interpretación y, en algunos casos, la omisión y el desconocimiento de los docentes como agentes educativos del Estado. En este sentido, se puede asegurar que la acción política de los docentes en las prácticas pedagógicas es un proceso constante y continuo de creación, por medio del cual buscan responder a las expectativas del Estado, no obstante, está determinado por sus intereses, sus recursos profesionales, sus visiones de mundo, sus concepciones de infancia, entre muchos otros factores, que hacen que se produzcan sentidos locales a la política instituida por la norma oficial (Menezes-Viana et al., 2015).

En línea con lo anterior, la política en las prácticas pedagógicas en la modalidad institucional de educación inicial se estructura a partir de tres derroteros que van marcando los caminos a seguir: el normativo, que ya fue mencionado; las tradiciones, que salvaguardan la cultura y la historicidad de estas prácticas pedagógicas de educación inicial en la modalidad institucional, y cuya importancia radica en que "son pautas del pasado que aún subsisten y guían las formas de ser, de estar, de actuar y de vivir en la educación inicial hoy" (Jackson, citado por Vargas-González, p. 245); y algunas alternativas a las tradiciones. 
Sobre las tradiciones que orientan esta política en las prácticas pedagógicas en la modalidad institucional de educación inicial se pueden señalar las siguientes premisas: i) en las prácticas pedagógicas de educación inicial en la modalidad institucional el docente es quien posee el saber que se va a enseñar, algo que se inscribe en lo que Philip W. Jackson (2012) denominó la tradición mimética, que se centra en la trasmisión de conocimientos fácticos y metodológicos de una persona a otra, a través de un proceso esencialmente imitativo, y explica, en gran medida, por qué aún es válido que a través de la repetición se pretenda fijar contenidos, habilidades e ideas que se pueden juzgar como correctos e incorrectos en los niños; ii) decidir, planear y organizar la práctica pedagógica de la modalidad institucional de educación inicial es responsabilidad del docente; y iii) en la práctica pedagógica de la modalidad institucional de educación inicial se forma al sujeto social, a la niña o al niño que vive en comunidad.

En la política educativa, en las prácticas observadas en CDI y HI aparecen por momentos formas alternativas de estar, actuar, ser y vivir en las prácticas pedagógicas, que se fundamentan en la necesidad de fortalecer la participación de los niños. Así pues, algunas veces los niños y las docentes comparten sus ideas, sus hipótesis y su entendimiento en la percepción compartida, lo que lleva a la generación de nuevas ideas, hipótesis, comprensiones e inquietudes. Otras veces (muy pocas como ya se mencionó), los niños se expresan con libertad y con seguridad al sentir que sus aportes son valiosos, y que no hay una única respuesta a las cuestiones que se plantean. Cuando esto sucede los niños construyen sus conocimientos y sus identidades a partir de lo que hacen, de las relaciones que establecen y de los recursos que tienen a su disposición, lo cual hace tangible el auténtico papel de la práctica pedagógica (Dahlberg et al., 2005).

El diálogo entre los tres derroteros expuestos es un punto de partida para plantear posibles acciones que le permitan a la educación inicial en Colombia transformarse y avanzar desde un enfoque ecológico, que recupera "la agencia de los sujetos como hacedores de política" (Gandulfo, 2015, p. 24), reconociendo así la coexistencia (Adlerstein-Grimberg, 2008) de diversos sentidos en las prácticas pedagógicas en la modalidad institucional de educación inicial y haciendo "imposible despojarlas de su contexto y esperar una suerte de estandarización desde una perspectiva aparentemente neutra" (Vargas-González, 2020, p. 253).

Dos aspectos claves para tomar en consideración, en el marco de dicho diálogo, son: i) la discusión, reflexión y toma de postura crítica sobre la enseñanza, como un proceso que define a los docentes y a sus prácticas pedagógicas, de tal forma que son ellos quienes toman las decisiones, conscientes y sopesadas, sobre su actuar pedagógico y, en consecuencia, 
tienen mayor claridad sobre cómo influyen o no en el desarrollo y aprendizaje de los niños; ii) fortalecer la noción del niño como un ciudadano en el aquí y en el ahora, que merece una actitud de respeto por sus singularidades, es actor en la construcción de su propia vida, y con teorías e ideas que merecen ser cuestionadas, desafiadas y discutidas (Corrales-Mejía, 2014; Dahlberg et al., 2005).

Figura 7.

Horizontes que guían la política en las prácticas pedagógicas en la modalidad institucional de educación inicial en Colombia

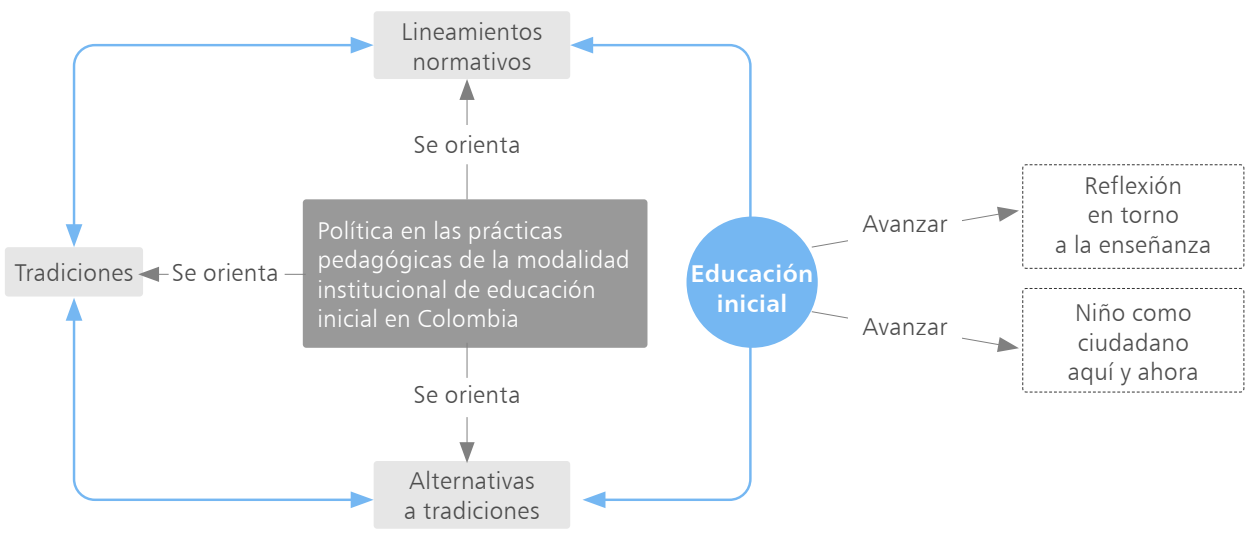

Nota: Elaboración propia.

En conclusión, en la práctica pedagógica se hace, se comprende y se vive el mundo; en otras palabras, es por esto que la política en las prácticas pedagógicas en la modalidad institucional de educación inicial en Colombia se expresa en términos de agencia y no solo de normatividad; esto reivindica las relaciones de creación entre las prácticas pedagógicas cotidianas de educación inicial en la modalidad institucional y los lineamientos educativos de la política pública dirigida a la primera infancia colombiana en el programa De Cero a Siempre.

\section{Aclaraciones y agradecimientos}

Investigación doctoral para el Doctorado en Educación de la Universidad de los Andes, Bogotá, Colombia. Beneficiaria convocatoria 727 - MinCiencias.

\section{Sobre la autora}

Ángela Patricia Vargas-González es licenciada en Pedagogía Infantil y magíster en Educación de la Pontificia Universidad Javeriana, Colombia. Doctora en educación de la Universidad de los Andes, Colombia. Becaria de MinCiencias. Docente de la Pontificia Universidad Javeriana, Colombia. 


\section{Referencias}

Adlerstein-Grimberg, C. (2008). Aportes de Néstor García Canclini y Paulo Freire a la superación de la perplejidad educativa. Revista de Pedagogía Crítica. Paulo Freire. (6), 39-49. DOI: https://doi.org/10.25074/07195532.6.477

Alaníz-Hernández, C. (2014). Implicaciones de la política educativa del nivel básico: la percepción de los docentes. Espiral, Estudios sobre Estado y Sociedad, 21(59), 29-67. http://www.scielo.org.mx/scielo.php?script=sci_arttext\&pid $=\mathrm{S} 1665-05652014000100002$

Amaro, I. (2014). Avaliar ou examinar a escola? Performatividade, regulação e intensificação do trabalho docente. Impulso. 24(61), 109-127. http://dx.doi. org/10.15600/2236-9767/impulso.v24n61p109-127

Angrosino, M. V. (2015). Recontextualización de la observación. Etnografía, pedagogía y las perspectivas de una agenda pública progresista. En N. K. Denzin, y Y. S. Lincoln (coords.), Manual de Investigación Cualitativa (Vol. 4, pp. 203-224). Gedisa Editorial.

Asprella, G. (2016). La interpelación de lo cotidiano a las políticas educativas. En G. Asprella y M. E. Vicente (coords.), La vida cotidiana en las instituciones educativas. Una mirada pedagógica a la gestión de la escuela secundaria (10-20). Editorial de la Universidad de la Plata.

Bartlett, L. \& Vavrus, F. (2017). Rethinking Case Study Research. A Comparative Approach. Routledge.

Baxter, J. (2016). Who governs educational change? The paradoxes of state power and the pursuit of educational reform in post-neoliberal Ecuador (2007-2015) [Tesis de doctorado, University de Libraries]. http://hdl.handle. net/1903/18599

Cerna, L. (2013). The Nature of Policy Change and Implementation: A Review of Different Theoretical Approaches. OECD. https://www.oecd.org/edu/ceri/ The\%20Nature\%20of\%20Policy\%20Change\%20and\%20Implementation.pdf

Charmaz, K. (2017). The Power of Constructivist Grounded Theory for Critical Inquiry. Qualitative Inquiry, 23(1), 34-45. https://doi.org/10.1177/1077800 416657105

Charmaz, K. (2013). La teoría fundamentada en el siglo XXI. Aplicaciones para promover estudios sobre la justicia social. En N. K. Denzin, y Y. S. Lincoln (Coords.), Manual de Investigación Cualitativa. Las estrategias de investigación cualitativa (Vol. 3, pp. 270-325). Gedisa editorial.

Corrales-Mejía, M. C. (2014). Entre lo Apolíneo y lo Dionisíaco: naturaleza de las interacciones adulto-niño en la vida cotidiana. Fundación Centro Internacional y Desarrollo Humano CINDE.

Creswell, J. W. (2013). Qualitative inquiry and research desing: choosing among five approaches. SAGE Publications.

Dahlberg, G., Moss, P. y Pence, A. (2005). Más allá de la calidad en educación infantil. Editorial GRAÓ.

De Castro-Cerqueira, A. (2016). A pesquisa sobre política educacional: estudo sobre o GT5 da ANPEd. Revista de Estudios Teóricos y Epistemológicos en Política Educativa, 1(1), 10-29. https://revistas2.uepg.br/index.php/retepe/ article/view/10447 
De Souza, Â. (2016). A política educacional e seus objetos de estudo. Revista de Estudios Teóricos y Epistemológicos en Política Educativa, 1(1), 75-89. https://revistas2.uepg.br/index.php/retepe/article/view/10450

Del Castillo-Alemán, G. (2012). Las políticas educativas en México desde una perspectiva de política pública: gobernabilidad y gobernanza. Magis, 4(9), 637-652. https://revistas.javeriana.edu.co/index.php/MAGIS/article/ view/3580

Denzin, N. K., y Lincoln, Y. S. (2012). Introducción general. La investigación cualitativa como disciplina y como práctica. En N. K. Denzin, y Y. S. Lincoln (Coords.), Manual de Investigación Cualitativa. El campo de la investigación cualitativa (Vol. 1, pp. 43-101). Gedisa Editorial.

Flores-Crespo, P. (2013). El enfoque de la política basado en la evidencia. Análisis de su utilidad para la educación de México. Revista Mexicana de Investigación educativa, 18(56), 265-290. http://www.redalyc.org/articulo. oa?id $=14025581012$

Gandulfo, C. (2015). Itinerario de una investigación sociolingüística en colaboración con niños y maestros en un contexto bilingüe guaraní-castellano en la provincia de Corrientes, Argentina. Education Policy Analysis Archives, 23(96). http://dx.doi.org/10.14507/epaa.v23.2048

Garcés-Gómez, J. y Jaramillo Jaramillo, I. (2008). De la autonomía a la evaluación de calidad: gestión educativa, reformas legislativas e investigación de los maestros y las maestras en Colombia (1994-2006). Revista Educación y Pedagogía, XX(51), 175-187. http://aprendeenlinea.udea.edu.co/revistas/ index.php/revistaeyp/article/view/9904

Grant-Lewis, S. \& Naidoo, J. (2004). Whose Theory of Participation? School Governance Policy and Practice in South Africa. Current Issues in Comparative Education, 6(2), 100-112. https://www.tc.columbia.edu/cice/pdf/25729_6_2_ GrantLewis_Naidoo.pdf

Heras, A. I. (2015). Práctica cotidiana escolar, reflexión docente y posicionamiento en política pública. Análisis de intercambios en asambleas semanales. Archivos Analíticos de Políticas Educativas, 23(98). http://dx.doi.org/10.14507/ epaa.v23.2033

Herrera, J. D. y Martínez, Á. (2018). El saber pedagógico como saber práctico. Pedagogía y Saberes, (49), 9-26. http://www.scielo.org.co/pdf/ppo/n19/2011804X-ppo-19-00009.pdf

Jaimes-Carvajal, G. \& Rodríguez-Luna, M. (2015). Convergencias, tensiones y rupturas en las políticas de formación e incentivos docentes en Bogotá D. C. (1996-2013). Revista Colombiana de Educación, 68, 113-148. http://www. scielo.org.co/pdf/rcde/n68/n68a06.pdf

Jackson, P. W. (2012). Práctica de la enseñanza. Amorrortu Editores.

Kemmis, S., Wilkinson, J., Edwards-Groves, C., Hardy, I., Grootenboer, P. y Bristol. L. (2014). Changing Practices, Changing Education. Springer.

Kemmis, S. \& Edwards-Groves, C. (2018). Understanding Education. History, Politics and Practice. Springer.

Martínez-Rizo, F. (2012). Procedimientos para el estudio de las prácticas docentes. Revisión de la literatura. Revista Electrónica e Investigación y Evaluación Educativa, 18(1), 1-22. https://ojs.uv.es/index.php/RELIEVE/article/view/2976 
Ministerio de Educación Nacional. MEN. (2017). Bases Curriculares para la Educación Inicial y Preescolar. Referentes técnicos para la educación inicial en el marco de la atención integral. Colombia.

Ministerio de Educación Nacional. MEN. (2014a). El arte en la educación inicial. Documento $N^{\circ} 21$. Serie de orientaciones pedagógicas para la educación inicial en el marco de la atención integral. Colombia.

Ministerio de Educación Nacional. MEN. (2014b). El juego en la educación inicial. Documento $N^{\circ}$ 22. Serie de orientaciones pedagógicas para la educación inicial en el marco de la atención integral. Colombia.

Ministerio de Educación Nacional. MEN. (2014c). La exploración del medio en la educación inicial. Documento No 24. Serie de orientaciones pedagógicas para la educación inicial en el marco de la atención integral. Colombia.

Ministerio de Educación Nacional. MEN. (2014d). La literatura en la educación inicial. Documento No 23. Serie de orientaciones pedagógicas para la educación inicial en el marco de la atención integral. Colombia.

Ministerio de Educación Nacional. MEN. (2014e). Orientaciones para el cumplimiento de las condiciones de calidad en la modalidad institucional de educación inicial. Guía No 51. Serie de orientaciones para favorecer la calidad de la educación inicial en el marco de la atención integral. Colombia.

Ministerio de Educación Nacional. MEN. (2014f). Seguimiento al desarrollo integral de las niñas y los niños en la educación inicial. Documento No 25. Serie de orientaciones pedagógicas para la educación inicial en el marco de la atención integral. Colombia.

Ministerio de Educación Nacional. MEN. (2014g). Sentido de la educación inicial. Documento $N^{\circ} 20$. Serie de orientaciones pedagógicas para la educación inicial en el marco de la atención integral. Colombia.

Menezes-Viana, G. M., Munford, D., Ferreira, M. S. \& Fernandes, P. C. (2015). Relações teoriaprática na formação de professores de Ciências: um estudo das interações discursivas no interior de uma disciplina acadêmica. Archivos Analíticos de Políticas Educativas, 23(100). http://dx.doi.org/10.14507/epaa. v23.2049

Miñana-Blasco, C. \& Arango-Vargas, C. (2011). Educational Policy, Anthropology, and the State. En B. Levinson, y M. Pollock, (Eds.), A Companion to the Anthropology of Education (pp. 368-387). Blackwell Publishing.

Miranda-Camacho, G. (2006). Hacia una visión hermenéutica crítica de la política educativa. Revista Ciencias Sociales, I-I/(111-112), 101-118. https://www. redalyc.org/pdf/153/15311209.pdf

Navas-Gómez, G. \& Reynoso-Jaime, J. (2015). Conceptualización y reflexión sobre la práctica educativa en un programa de formación continua para docentes de educación media superior en México. Revista Educación, 39(1), 137-157. http://dx.doi.org/10.15517/revedu.v39i1.17862

Patel, L. (2016). Reaching Beyond Democracy in Educational Policy Analysis. Educational Policy. 30(1), 114-127. https://doi.org/10.1177/0895904815614915

Pérez-Castro, J. (2009). El efecto Frankenstein: las políticas educativas mexicanas y su impacto en la profesión académica. Espiral, Estudios sobre Estado y Sociedad. XVI(46), 61-95. http://www.scielo.org.mx/scielo.php?script=sci_ar ttext\&pid $=$ S1665-05652009000100003 
Ponce-Grima, V. (2009). Investigación y políticas educativas. Revista Electrónica Sinéctica, (33). http://www.redalyc.org/pdf/998/99812140001.pdf

Presidencia de la República, Colombia. (2012). Comisión Intersectorial de Primera Infancia. Atención Integral: Prosperidad para la Primera Infancia. Colombia. http://www.deceroasiempre.gov.co/QuienesSomos/Documents/CartillaAtencion-Integral-prosperidad-para-primera-infancia.pdf

Robledo-Castro, M. (2015). Componentes fundamentales para la formulación de una política de formación integral en la educación básica y media, en el marco de las políticas y tendencias mundiales y locales de desarrollo humano, social, educativo y económico. Revista EDUCyT, 8, 18-36. https://die. udistrital.edu.co/revistas/index.php/educyt/article/view/237

Rockwell, E. (2014). De huellas, bardas y veredas: una historia cotidiana en la escuela. En E. Rockwell (Coord.), La escuela cotidiana (6a reimpresión) (pp. 13-57). Fondo de Cultura Económica.

Roth-Deubel, A. N. (2017). Las políticas públicas y sus principales enfoques analíticos. En A. N. Roth Deubel (Ed.), Enfoque para el análisis de políticas públicas (pp. 17-65). Universidad Nacional de Colombia.

Roth-Deubel, A. N. (septiembre, 2014). Investigación e intervención en políticas públicas: hacia un análisis en perspectiva crítica. [Ponencia III Congreso de la ACCPOL]. Cali - Popayán, Colombia.

Stake, R. (2013). Estudios de casos cualitativos. En N. K. Denzin, y Y. S. Lincoln (Coords.), Manual de Investigación Cualitativa (Vol. 3, pp. 154-197). Gedisa Editorial.

Subirats, J., Knoepfel, P., Corinne, L. \& Varonne, F. (2008). Análisis y gestión de políticas públicas. Editorial Ariel.

Unamuno, V. (2015). Los hacedores de la EIB: un acercamiento a las políticas lingüísticoeducativas desde las aulas bilingües del Chaco. Archivos Analíticos de Políticas Educativas, 23(101). http://dx.doi.org/10.14507/epaa.v23.2061

Valencia-Aguirre, A. (2009). La razón narrativa frente a la política pública: una lección desde las subjetividades. Sinética, (33), 1-14. https://www.redalyc. org/articulo.oa?id=99812140003

Vargas-González, A. (2020). La política en las prácticas: análisis de las prácticas pedagógicas en la modalidad institucional de educación inicial en Colombia y su relación con la política pública "De Cero a Siempre" [Tesis de doctorado, Universidad de los Andes]. http://hdl.handle.net/1992/48388

Vergara-Arboleda, M. (2014). La identidad de la educadora infantil. Elementos para su comprensión. Pedagogía y Saberes, (41), 111-120. https://doi.org/1 $0.17227 / 01212494.41$ pys 111.120

Vidiella, J. \& Larraín, V. (2015). El papel de las condiciones de trabajo en la construcción de la identidad docente: Corporalidades, afectos y saberes. Revista Mexicana de Investigación Educativa, 20(67), 1281-1310. http://www.scielo. org. $\mathrm{mx} /$ scielo.php?script=sci_arttext\&pid $=\$ 1405-66662015000400013$

Viscaíno, A. (2006). El aprendizaje de la práctica docente. Ingreso a la docencia: entre mimetizarse, parecerse y diferenciarse. Cuadernos de Educación, 4(4), 201-211. https://revistas.unc.edu.ar/index.php/Cuadernos/article/view/701

Yanow, D. (2014). Interpretive Analysis and Comparative Research. En I. Engeli y C. Rothmayr (eds.), Comparative policy studies: Conceptual and methodological challenges (pp. 131-159). Palgrave Macmillan. 